\title{
Personalized participatory medicine: sharing knowledge and uncertainty
}

\author{
David Gurwitz ${ }^{*}$ and Jeantine E Lunshof $2,3,4$ \\ See research article: http://genomemedicine.com/content/3/10/64
}

\begin{abstract}
Informing patients about risks and benefits of alternative treatment options and choosing between them is becoming a bigger challenge as knowledge about the relationship between the individual's genetic profile and the efficacy and safety of available medications accumulates. Putting personalized medicine into practice requires new modes of information sharing and decision making by patient and physician. This is illustrated by a case study on treatment choices of breast cancer patients following genotyping for CYP2D6, recently published in Genome Medicine.
\end{abstract}

The complexity of choosing a particular treatment for an individual patient while keeping her informed about the relevant options and considerations keeps increasing as personal genetic information becomes more commonly available. This is leading clinicians and patients to question their role in the decision-making process. For example, what role should patients take in choosing between alternative treatment options, in particular when the benefits and risks of each option are not crystal clear? To what extent should clinicians share their own hesitations about the best treatment choice, exposing their patients to the incomplete knowledge about each alternative? How should clinicians take such decisions without exposing patients to superfluous stress when current knowledge about the advantages and drawbacks of available therapy options is far from complete?

These questions, and the doctor's dilemma, have long been the topic of public discourse. Over 800 years ago, Maimonides, a prominent Jewish philosopher and

\footnotetext{
*Correspondence: gurwitz@post.tau.ac.il

'Department of Human Molecular Genetics and Biochemistry, Sackler Faculty of

Medicine, Tel-Aviv University, Tel-Aviv 69978, Israel
}

Full list of author information is available at the end of the article practicing physician, wrote that the risk of a wrong decision is preferable to the terror of indecision. Although this remains as true as ever, should we not be asking what role patients have in taking a treatment decision - even when current knowledge is incomplete? Such questions seem to be more pertinent as we enter the age of personal genomes, when an individual's pharmacogenomic data may affect their choice between treatment options [1-3]. Can patients comprehend complex diagnostic information and act on it when they face a choice between alternative therapeutic options, based on their personal genomic data? In other words, should patients be made aware of the fine details of current medical knowledge, including the gaps in it, when crucial treatment decisions have to be made? Inevitably, some of those decisions may later turn out to have been the wrong ones for them.

\section{A real-world example}

Wendy Lorizio and colleagues [4] have examined this charged issue in a real-world personalized medicine scenario by following the treatment choices of 235 breast cancer patients currently taking or planning to take tamoxifen for prevention of cancer recurrence and who were offered the CYP2D6 genotyping test. Their study is a fine example of our current knowledge limitations: at the time of conducting their CYP2D6 genotyping and follow-up patients survey (March 2008 to May 2010), most published studies, based on retrospective data, indicated that individuals having a CYP2D6 poor metabolizer genotype (predictive of complete lack of the enzyme activity) were less likely to benefit from tamoxifen for the prevention of breast cancer recurrence [5,6]. However, more recent meta-analysis and studies cast doubt about the relevance of CYP2D6 genotypes for breast cancer recurrence in tamoxifen-treated patients $[7,8]$. Thus, it could well be that a similar study taking place today would find other results, namely that patients would be less likely to change from tamoxifen to another drug following genotyping. As long as no consensus has been reached on the effect of CYP2D6 genotypes on the efficacy of tamoxifen for preventing breast cancer 
recurrence, monitoring the serum level of endoxifen, its active metabolite, seems the most appropriate biomarker for adjusting tamoxifen dosages [9]. Including this biomarker as a decision making tool in breast cancer therapy seems to be justified at our currently incomplete state of knowledge. Moreover, it will remain a valuable biomarker once endoxifen itself, currently in clinical trials, is eventually approved as a drug [10].

The study by Lorizio et al. [4] found that 46\% (6 of 13) of the breast cancer patients prescribed tamoxifen and genotyped as poor CYP2D6 metabolizers elected to change their medication to another drug within the following 6 months. This crucial treatment decision, while obviously taken along with their attending physicians, must have been affected by their participation in the informational session held by the researchers before the genetic testing, in which the results of studies examining the effects of CYP2D6 genotypes on breast cancer recurrence were presented. Notably, the authors [4] found that about half the patients had previous knowledge about the relevance of CYP2D6 genotypes for tamoxifen therapy, with the source of this knowledge being their nurses or clinicians, the medical literature or the general media (internet, TV and newspapers). Yet it seems that performing the genotyping tests and learning about their results in a medical setting affected the decision on switching treatment.

\section{Moving towards personalized medicine}

This study [4] does not examine the extent to which the decision about changing the medication was driven by the patients or their clinicians. The genotyping results were transferred to patients through their attending physicians, who did not receive specific recommendations along with the laboratory results. It would have been of interest to also interview the clinicians and find out about their role and considerations in taking this decision; however, this would require a larger study, as in this one only 13 patients of the 235 who were genotyped were found to be CYPD6 poor metabolizers [4]. However, this study [4] illustrates that when genotyping relevant to drug response is carried out in a clinical setting along with informing patients about the test implications in advance of the testing, a decision about medication change followed for about half the patients whose test results indicated (at that time) that they were unlikely to benefit from tamoxifen.

This study conveys important insights for moving personalized medicine forward: offering patients pharmacogenetic testing in the clinical setting along with an educational session on the test relevance for their medication choices is an effective route for taking informed treatment decisions. The lesson is that personalized medicine can be practiced in a participatory way. The challenge will be to keep medicine participatory and patients fully informed when medicine and personal genomes meet - which may not be as far away as it seemed just a decade ago.

Competing interests

The authors declare that they have no competing interests.

\section{Author details}

'Department of Human Molecular Genetics and Biochemistry, Sackler Faculty of Medicine, Tel-Aviv University, Tel-Aviv 69978, Israel. ${ }^{2}$ Faculty of Health,

Medicine and Life Sciences, Maastricht University, Maastricht, The Netherlands. ${ }^{3}$ Department of Molecular Cell Physiology, Faculty of Earth and Life Sciences, VU University Amsterdam and Netherlands Institute for Systems Biology (NISB), De Boelelaan 1085, 1081 HV Amsterdam, The Netherlands. ${ }^{4}$ Ethics Consultant, Center for Excellence in Genomic Science and Personal Genome Project, Department of Genetics, Harvard Medical School, Boston, MA 02115 , USA.

\section{Published: 27 October 2011}

\section{References}

1. Goldstein DB: Pharmacogenetics in the laboratory and the clinic. NEng/J Med 2003, 348:553-556.

2. Ashley EA, Butte AJ, Wheeler MT, Chen R, Klein TE, Dewey FE, Dudley JT, Ormond KE, Pavlovic A, Morgan AA, Pushkarev D, Neff NF, Hudgins L, Gong L, Hodges LM, Berlin DS, Thorn CF, Sangkuhl K, Hebert JM, Woon M, Sagreiya H, Whaley R, Knowles JW, Chou MF, Thakuria JV, Rosenbaum AM, Zaranek AW, Church GM, Greely HT, Quake SR, et al:: Clinical assessment incorporating a personal genome. Lancet 2010, 375:1525-1535.

3. Wang L, McLeod HL, Weinshilboum RM. Genomics and drug response. NEngl J Med 2011, 364:1144-1153.

4. Lorizio W, Rugo H, Beattie MS, Tchu S, Melese T, Melisko M, Wu AH, Lawrence HJ, Nikoloff M, Ziv E: Pharmacogenetic testing affects choice of therapy among women considering tamoxifen treatment. Genome Med 2011, 3:64

5. Goetz MP, Knox SK, Suman VJ, Rae JM, Safgren SL, Ames MM, Visscher DW, Reynolds C, Couch FJ, Lingle WL, Weinshilboum RM, Fritcher EG, Nibbe AM, Desta Z, Nguyen A, Flockhart DA, Perez EA, Ingle JN: The impact of cytochrome P450 2D6 metabolism in women receiving adjuvant tamoxifen. Breast Cancer Res Treat 2007, 101:113-121.

6. Schroth W, Goetz MP, Hamann U, Fasching PA, Schmidt M, Winter S, Fritz P, Simon W, Suman VJ, Ames MM, Safgren SL, Kuffel MJ, Ulmer HU, Boländer J, Strick R, Beckmann MW, Koelbl H, Weinshilboum RM, Ingle JN, Eichelbaum M, Schwab M, Brauch H: Association between CYP2D6 polymorphisms and outcomes among women with early stage breast cancer treated with tamoxifen. JAMA 2009, 302:1429-1436.

7. Seruga B, Amir E: Cytochrome P450 2D6 and outcomes of adjuvant tamoxifen therapy: results of a meta-analysis. Breast Cancer Res Treat 2010, 122:609-617.

8. Siegelmann-Danieli N, Kurnik D, Lomnicky Y, Vesterman-Landes J, Katzir I, Bialik M, Loebstein R: Potent CYP2D6 inhibiting drugs do not increase relapse rate in early breast cancer patients treated with adjuvant tamoxifen. Breast Cancer Res Treat 2011, 125:505-510.

9. Barginear MF, Jaremko M, Peter I, Yu C, Kasai Y, Kemeny M, Raptis G, Desnick $\mathrm{RJ}$ : Increasing tamoxifen dose in breast cancer patients based on CYP2D6 genotypes and endoxifen levels: effect on active metabolite isomers and the antiestrogenic activity score. Clin Pharmacol Ther 2011, 90:605-611.

10. Ahmad A, Shahabuddin S, Sheikh S, Kale P, Krishnappa M, Rane RC, Ahmad I: Endoxifen, a new cornerstone of breast cancer therapy: demonstration of safety, tolerability, and systemic bioavailability in healthy human subjects. Clin Pharmacol Ther 2010, 88:814-817.

doi:10.1186/gm285

Cite this article as: Gurwitz D, Lunshof JE: Personalized participatory

medicine: sharing knowledge and uncertainty. Genome Medicine 2011, 3:69. 